Stacy Alaimo

University of Texas, Arlington, Texas, Estados Unidos

\title{
Feminismos transcorpóreos e o espaço ético da natureza
}

\begin{abstract}
Resumo: Postula-se, neste artigo, uma maior aproximação entre os estudos sobre o corpo, mais exatamente o feminismo corpóreo, e o conhecimento ambiental na filosofia e nos estudos culturais. Devido à associação tradicional da natureza a posturas essencialistas, a importância da materialidade tem sido pouco explorada na teoria feminista. Com a utilização do conceito de transcorporalidade - o tempo e espaço em que a corporalidade humana é inseparável da "natureza" ou do "ambiente" - como lugar teórico ou espaço epistemológico, modos de análise mais ricos e mais complexos podem aproximar "os confusos territórios do material e do discursivo, do natural e do cultural, do biológico e do textual".

Palavras-chave: Feminismo transcorpóreo; Natureza-mais-que-humana; Teoria feminista ambiental.
\end{abstract}

\section{(c) (7)}

Esta obra está sob licença Creative Commons.

' Publicado originalmente em Alaimo e Hekman (2007, p. 237264).
Apesar da vasta produção acadêmica sobre "o corpo" na teoria feminista e nos estudos culturais, assim como do crescimento simultâneo da filosofia, da crítica e dos estudos culturais ambientalistas, essas duas correntes raramente se misturam. ${ }^{1}$ Embora com relevantes exceções, no geral, se desenvolveram duas discussões isoladas - discussões que se teriam tornado mais complexas e ricas por meio de colisões e convergências. A maioria das análises feministas sobre o corpo em particular distancia seu foco da "natureza" como um topos. Com efeito, de um ponto de vista ambientalistafeminista, um dos legados mais nefastos do feminismo pósestruturalista e pós-moderno tem sido a acelerada "fuga da natureza", instigada pelos rígidos compromissos com o construcionismo social e pela determinação em erradicar todo e qualquer vestígio de essencialismo. A natureza, tida como um acessório do essencialismo, tem servido como abjeto para o feminismo - aquilo que, ao ser expelido do "eu", funciona para definir esse "eu" (Julia KRISTEVA, 1982, p. 1-4). Esse movimento já convencional epitomiza um dos argumentos centrais deste trabalho: que a tendência predominante da teoria feminista nas últimas décadas tem 
${ }^{2}$ Ver Val Plumwood (1993) para uma análise dos estudos sobre as mulheres e a natureza. sido a de diminuir a importância da materialidade. Os paradigmas predominantes, na verdade, não negam a existência material dos corpos, mas tendem a focar exclusivamente em como os vários corpos têm sido produzidos discursivamente, o que acaba por conceber o corpo como matéria passiva, plástica. Como diz Elizabeth A. WILSON (1998), "o corpo no centro desses projetos é curiosamente abiológico - já que sua construção social, cultural, empírica ou física tem sido postulada contra ou fora de qualquer reivindicação supostamente biológica (p. 15). Isolar o corpo biológico, e, assim, quebrar suas interconexões evolucionárias, históricas e continuadas com o mundo material, pode não ser ética, política ou teoricamente desejável.

Felizmente, há outras opções. Uma delas seria a de enraizar o feminismo exatamente no campo que tem, há muito tempo, funcionado como abjeto. Gostaria de propor que nos colocássemos no que chamo de "transcorporalidade" - o tempo-espaço em que a corporalidade humana, em toda sua carnalidade material, é inseparável da "natureza" ou do "ambiente". A transcorporalidade, como um locus teórico, é um lugar em que as teorias corpóreas e ambientais se encontram e se misturam de forma produtiva. Além disso, o movimento entre a corporalidade humana e a natureza não humana exige ricos e complexos modos de análise que transitem através dos emaranhados territórios do material e do discursivo, do natural e do cultural, do biológico e do textual.

Possibilidades éticas e políticas cruciais emergem dessa "zona de contato" literal entre a corporalidade humana e a natureza mais-que-humana. Imaginar a corporalidade humana como transcorporalidade, em que o humano está sempre enredado com o mundo mais-que-humano, enfatiza - quanto a substância corpórea do humano é fundamentalmente inseparável do "ambiente". Torna-se difícil conceber a natureza como um mero pano de fundo para as aventuras do humano, ${ }^{2}$ uma vez que a "natureza" está sempre tão perto quanto a própria pele. Com efeito, pensar através dos corpos pode catalisar o reconhecimento de que o "ambiente", quase sempre imaginado como um espaço inerte e vazio ou como um "recurso" para uso humano, é, de fato, um mundo de seres carnais, com suas próprias necessidades, exigências e ações. Ao enfatizar o movimento através dos corpos, a transcorporalidade revela as trocas mútuas e as interconexões entre a corporalidade humana e o mais-quehumano. Mas, ao ressaltar que "trans" indica um movimento por meio de diferentes lugares, a transcorporalidade abre um "espaço" epistemológico que reconhece as muitas vezes imprevisíveis e indesejáveis ações dos corpos humanos, das criaturas não humanas, dos sistemas ecológicos, dos agentes químicos e de outros atores. A ênfase nas interconexões 
materiais da corporalidade humana com o mundo mais-quehumano e o concomitante reconhecimento de que a agência material precisa de epistemologias mais abrangentes nos permitem forjar posições éticas e políticas que possam contestar inúmeras realidades do final do século XX e início do século XXI, em que "humano" e "ambiental" não podem, absolutamente, ser pensados como coisas separadas: saúde ambiental, justiça ambiental, tráfico de toxinas e engenharia genética, entre outras.

\section{A teoria feminista e seu afastamento da natureza}

A natureza, como um conceito filosófico, um forte núcleo ideológico e um repositório cultural de normas e moralismo, tem sido, por muito tempo, usada contra mulheres, pessoas de cor, povos indígenas, homossexuais e classes pobres. Paradoxalmente, mulheres, a classe trabalhadora, os povos tribais e as pessoas de cor têm sido denegridas por sua suposta "proximidade" com a natureza, mesmo que homossexuais tenham sido acusados de "não naturais". Os significados contraditórios, onipresentes e historicamente variados da "natureza" a tornaram um locus crucial para várias lutas sociais feministas, incluindo o anarquismo e o socialismo feministas, o controle da natalidade, a igualdade racial e o lesbianismo. Em Undomesticated Ground: Recasting Nature as Feminist Space (2000), argumento que, pelo fato de "a mulher" ter sido definida na cultura ocidental como presa à "natureza" e, dessa forma, alijada do domínio da transcendência, da racionalidade, da subjetividade e do agenciamento humanos, a maior parte da teoria feminista esforçou-se para liberar a "mulher" da "natureza". De Simone de Beauvoir a Sherry Ortner, Juliet Mitchell, Gayle Rubin e Monique Wittig, a maior parte da teoria feminista transfere a "mulher" da categoria de natureza para o âmbito da cultura. Elaborados dentro de, e não contra, os dualismos predominantes, muitos argumentos e conceitos feministas importantes necessitam de uma rígida oposição entre natureza e cultura. Por exemplo, o conceito mais revolucionário da teoria feminista-o conceito de gênero como distinto do sexo biológico - está fundamentado numa oposição aguda entre natureza e cultura.

Além disso, embora possa ser difícil supervalorizar a força explanatória e polêmica das teorias feministas da construção social, tais teorias são assombradas pelas perniciosas noções de natureza que lhes dão ímpeto. Deixando de lado esse ímpeto, ao ser completamente removida da cultura, essa natureza - o repositório de essencialismo e stasis - permanece, mesmo assim, perigosamente intacta (Stacy ALAIMO, 2000, p. 4-14). Em vez de fugir dessa natureza aviltada, associada à 
${ }^{3}$ Ver Alaimo (2000) para mais informação sobre como as escritoras e teóricas dos Estados Unidos transformaram concepções específicas da natureza com diferentes fins políticos. corporalidade, falta de intelecto e passividade, seria mais produtivo para a teoria feminista empreender a transformação dos dualismos marcados pelo gênero - natureza, cultura, corpo, mente, objeto, sujeito, recurso, agenciamento e outros - que vêm sendo cultivados para diminuir e silenciar certos grupos de humanos e a vida não humana.

Contrapondo-se aos argumentos feministas de que as mulheres são criadas pela cultura e não pela natureza, um grupo variado de escritoras, ativistas e teóricas norteamericanas, do início do século XIX até o presente - incluindo Catherine Sedgwick, Mary Wilkins Freeman, Sarah Orne Jewett, as feministas darwinianas Antoinette Brown Blackwell e Eliza Burt Gamble, Mary Austin, as teóricas marxistas-feministas Mary Inman e Rebecca Pitts, Octavia Butler, Marian Engel e Jane Rule - se voltou para a natureza como o hábitat de sujeitos feministas. Suas formulações condenam a "fabricação" social das mulheres como "não naturais" e imaginam a natureza não como o terreno do essencialismo, mas como um hábitat para os feminismos pós-estruturalistas que buscam um apagamento de gênero, às vezes de forma queer, muitas vezes de modo incipiente. A feminista darwiniana Antoinette BROWN BLACKWELL (1875), em The Sexes Throughout Nature, volta-se para o "mundo inorgânico" para minar o significado cultural da diferença sexual, argumentando que

esses elementos e essas forças [da diferença sexual] constantemente mudam de lado, reorganizando-se indefinidamente com outras forças. Assim, o que pode ser reconhecido como masculino em uma situação, pode tornar-se feminino em outra (p. 44).

Em sua curiosa formulação, a matéria, sempre em transformação, expõe a rigidez das oposições sexuais na cultura. De forma semelhante, a escritora do início do século XX Mary Austin imagina o deserto como um terreno não domesticado para os sujeitos feministas, um lugar sem lei onde as indicações falham, o gênero se desintegra e os significados se desfazem. Esse rico e inovador grupo de escritoras feministas demonstra não só que é possível imaginar a natureza de tal forma que ela não seja reconhecida como base do essencialismo, mas também que o projeto de redefinir radicalmente a natureza há muito tempo tem estado no centro de um grande espectro de lutas sociais feministas. ${ }^{3}$

A corporalidade humana, especialmente a corporalidade feminina, está tão fortemente associada à natureza no pensamento ocidental, que não é de surpreender que o feminismo tenha sido assombrado não só pelo fantasma da natureza como repositório do essencialismo, mas, também, nas palavras de Lynda BIRKE (1999), pelo 'espectro da biologia' (p. 44). Birke denuncia que "a pressuposição de 
que alguns aspectos da "biologia" são fixos acaba por tornarse a narrativa mestra (mesmo que implicitamente) da qual as feministas e outras teóricas sociais tentam escapar" (p. 44). Nancy TUANA (1996), observando o recente reaparecimento da crença popular no determinismo racial e sexual, argumenta que "nós feministas temos sido epistemologicamente irresponsáveis ao manter uma base material fixa e essencial para a natureza humana, uma base que dá significado ao determinismo biológico" (p. 57). Somente ao se engajar diretamente com a matéria em si, o feminismo poderá fazer o que Tuana defende: tornar o determinismo biológico "um contra-senso". Por exemplo, ao invés de fixar o corpo biológico, Birke (1999) insiste na necessidade de compreendê-lo como "mutante e mutável, como transformável (p. 45). As células "se renovam constantemente", o osso "está sempre se remodelando" e o interior dos corpos "reage constantemente a mudanças internas ou externas, e age sobre o mundo" (p. 45).

Mesmo com esses parcos exemplos, fica claro que a noção de "biologia como destino", que há muito assombra o feminismo, depende de uma noção muito particular - talvez, até peculiar - de biologia, que pode, certamente, ser deslocada por outros modelos. Como a biologia, assim como a natureza, tem sido convocada para servir de escudo a normas racistas, sexistas e heterossexistas, torna-se crucial para as feministas invocar uma contra-biologia para auxiliar nossa luta. Por exemplo, Myra J. HIRD (2004), em "Naturally Queer", oferece uma abundância de exemplos biológicos que fazem o heterossexismo parecer, digamos, não natural. "A vasta maioria das células no corpo humano são intersexuadas"; "a maioria dos organismos em quatro entre cada cinco reinos não precisam de sexo para a reprodução", e, de forma surpreendente, o schizophyllum "tem mais de 28.000 sexos". Ela conclui argumentando que "talvez não possamos mais ter certeza de que é a natureza que permanece estática e a cultura que manifesta uma maleabilidade ilimitada" (p. 85-86, 88). Como uma forma de "conhecimento situado" (Donna HARAWAY, 1991), essa estranha biologia contesta não apenas o conteúdo e as ramificações da heterobiologia normativa, mas também seus argumentos de objetividade e neutralidade.

Talvez a única forma de verdadeiramente expulsar os fantasmas gêmeos da biologia e da natureza seja, paradoxalmente, dar-Ihes um corpo, permitindo que se materializem mais completamente, e examinar com cuidado suas materializações específicas.

\section{A virada material na teoria feminista}

Questionando-se sobre se se tornaria "uma traidora ou uma sobrevivente da era do (pós)estruturalismo", Teresa 
DE LAURETIS (2004), no recente simpósio da Critical Inquiry sobre "O Futuro da Crítica", corajosamente sugere que

talvez seja a hora de as ciências humanas reabrirem as questões da subjetividade, materialidade, discursividade, conhecimento, para refletir sobre o "pós" do pós-humano. Está na hora de quebrar o repositório de antigos esquemas conceituais e reinstalar a incerteza em todas as aplicações teóricas, começando com o primado da cultura e de suas várias "viradas": linguística, discursiva, performativa, terapêutica, ética, seja lá qual for (p. 368)

O que tem sido mais notadamente excluído pelo "primado da cultura" e pela virada em direção do linguístico e do discursivo é a "substância" da matéria. No entanto, intelectuais em três áreas da teoria feminista - teoria feminista corporal, feminismo ambientalista e estudos feministas da ciência - têm buscado conceituar maneiras inovadoras de entender o mundo material. O trabalho mais intrigante é o que, mesmo informado pelo pós-estruturalismo, pelo construcionismo social e pelos estudos culturais, força os limites desses próprios paradigmas; são escritoras imersas no cosmos da "virada linguística", mas que se voltam para o âmbito extradiscursivo ou extralinguístico. Teóricas como Donna Haraway, Vicki Kirby, Elizabeth Wilson e Karen Barad têm ampliado os paradigmas do pós-estruturalismo, do pósmodernismo e dos estudos culturais para que eles possam, de forma mais produtiva, considerar o agenciamento, o "pensamento" e a dinâmica de corpos e naturezas. Nenhuma dessas teóricas nega o profundo significado da cultura, da história e do discurso; no entanto, mesmo levando a sério a construção social ao insistirem que a cultura molda de forma profunda a nossa experiência, o que vemos e conhecemos, elas indagam sobre como a natureza não humana ou o corpo humano pode responder, resistir, ou, de alguma forma, afetar sua construção cultural. O aspecto mais desafiador desse projeto é o de repensar radicalmente a materialidade, a própria "substância" de corpos e naturezas. Algumas teóricas feministas como Moira Gatens, Claire Colebrook e Elizabeth Bray têm utilizado o trabalho de Spinoza e Deleuze como tradições que se opõem à virada linguística. Outras fazem releituras de teóricos centrais ao pós-estruturalismo por exemplo, Derrida (Vicki Kirby e Elizabeth Wilson), Michel Foucault (Ladelle McWhorter e Karen Barad), Judith Butler (Karen Barad) - e ampliam seus paradigmas para o âmbito do mundo material. Juntas, essas e algumas outras teóricas constituem a "virada material" na teoria feminista, uma onda da teoria feminista que leva a sério a materialidade.

Teóricas como Karen BARAD (1988) marcam um afastamento decisivo da teoria feminista recente, que rotula qual-

914 Estudos Feministas, Florianópolis, 25(2): 909-934, maio-agosto/2017 
${ }^{4}$ Haraway (2003) explica que 0 ciborgue foi criado para "ajudar o feminismo nos tempos da Star Wars da era Reagan em meados da década de 1980", mas que "no final do milênio, os ciborgues não mais podiam funcionar como cães pastores arrebanhando fragmentos do pensamento crítico" ( p. 4). Substituindo os ciborgues pelos caninos, Haraway insiste que cães são "presenças carnais mate-riais e semióticas", e não apenas "substitutos da teoria" (p. 5). quer movimento em direção à materialidade de "essencialista". Susan BORDO (1998) conta uma história perturbadora sobre como foi relegada ao ostracismo em um encontro de teoria feminista por ter pronunciado a palavra "material" ( $p$. 88) - apesar de que suas ricas e complexas análises nunca tenham subestimado o poder de forças sociais e políticas. Embora os feminismos materialistas levem a matéria muito a sério, eles não podem, de forma alguma, ser rotulados de essencialistas, uma vez que reformulam radicalmente as próprias bases do essencialismo. Eles não apelam para uma natureza ou um corpo humano anteriores ao discurso, mas trabalham para entender a materialidade como coconstituída por várias formas de poder e conhecimento, algumas mais ou menos "culturais" e outras mais ou menos "naturais", embora essas distinções venham se tornando cada vez mais problemáticas. Com efeito, ao utilizar esses termos, eu mesma me dou conta de sua impossibilidade, já que a maior parte do feminismo material embaralha a oposição naturezacultura.

Modos tão radicais de repensar o material são difíceis de sustentar num contexto teórico tão completamente orientado para o discursivo. Por exemplo, a figura provocativa e influente do ciborgue de Donna Haraway (1991), que desestabiliza os dualismos fundadores do pensamento ocidental, incluindo a oposição natureza/cultura, é celebrada pela maior parte da teoria feminista e dos estudos culturais como uma figura que dilui o limite entre o humano e a tecnologia mas, de forma significativa, nessa mais recente "fuga da natureza", o ciborgue é raramente aceito como um amálgama de "humano" e "natureza". (Talvez seja por isso que Haraway tenha se distanciado dessa celebrada figura e se voltado para os caninos em seu trabalho mais recente. ${ }^{4}$ ) Assim, os estudos culturais feministas, profundamente influenciados por teorias da construção social e discursiva, abraçaram significativamente o ciborgue como um construto social e tecnológico, mas ignoraram, na sua maioria, a matéria do ciborgue, uma materialidade que é tão biológica quanto tecnológica, tão carnal quanto mecânica, já que o ciborgue incentiva a relação humana tanto com animais quanto com máquinas (HARAWAY, 1991, p. 154). Mais perturbador ainda, a constante recodificação do ciborgue como tecnológico mas não como biológico - assemelha-se a um tipo de neo(super)humanismo, no qual o Homem/Mulher/Máquina finalmente transcende a natureza. No entanto, os escritos de Haraway, bem como os de outras teóricas materialistafeministas, demonstram que é possível repensar radicalmente a materialidade exatamente ampliando, reconfigurando e retrabalhando muitos dos modelos teóricos da virada linguística.

Estudos Feministas, Florianópolis, 25(2): 909-934, maio-agosto/2017915 
A virada material na teoria feminista concebe a matéria de várias formas: como material-semiótica, intercorporal, performativa, agencial, até letrada. Enquanto que estudos da corporalidade humana de orientação discursiva ficam confinados aos limites corpóreos do humano, os feminismos materialistas ampliam a questão do humano ao considerar modelos de extensão, interconexão, troca e separação. Embora muitas das teorias que vou discutir não estejam focadas nem na natureza nem no ambientalismo, sua reconceiłuação da materialidade e, especialmente, das relações entre a corporalidade humana e o mundo maisque-humano, tem um significado relevante para a filosofia ambientalista. E, na direção oposta, muitos dos correntes debates na filosofia ambientalista sobre a agência da natureza e sobre a possibilidade de epistemologias mais abrangentes são importantes para os modelos emergentes de materialidade na teoria feminista.

\section{Agência sem sujeitos}

Uma das questões mais importantes e espinhosas que brota de uma reconsideração radical da matéria é a questão da agência. Se vamos entender a natureza como algo que não seja apenas um recurso passivo para a exploração do Homem, e se vamos entender o corpo humano como algo além de uma tabula rasa aguardando a inscrição da cultura, temos que reconceituar corpos e naturezas de forma a reconhecer suas ações. Linda Birke (1999) argumenta que é crucial para as feministas "insistir em maneiras mais complexas e matizadas de entender os processos biológicos"(p. 48). Ela defende que feministas "renomeiem a natureza através da complexidade e da transformação" para "questionar os persistentes dualismos" que alimentam os dualismos de gênero (1999, p. 48). O conceito de agência dos corpos biológicos é crucial para entender entidades biológicas como complexas e em constante transformação. BIRKE argumenta, por exemplo, que se pode dizer que "órgãos internos e tecidos agem", e, mais amplamente, que os corpos biológicos não são nem passivos nem mecanicamente determinados, e, sim, exibem "reações ativas a mudança e contingências" (p. 45).

A filosofia ambiental e os estudos da ciência oferecem ricas e reveladoras discussões sobre agenciamento que podem ser benéficas para as teóricas da corporalidade. Conceber a agência da natureza (de forma não antropomórfica, nem reducionista, nem inconsequente) tem sido um problema central para o desmantelamento de discursos que concebem a natureza como uma terra nullius, um território vazio, esvaziado de tudo aquilo que a cultura reclama para sua autodefinição. É difícil, no entanto, imagi- 
nar como seria a agência num sentido outro que não o humano. Como é possível entender a agência sem um sujeito, ações sem atores? Como se pode repensar a matéria como atividade e não como substância passiva?

Há muito que Carolyn MERCHANT (1989) insiste na necessidade de historiadoras ambientalistas reconhecerem a agência da natureza. Em Ecological Revolutions: Nature, Gender, and Science in New England, ela "reafirma a ideia da natureza como um ator social" (p. 7) - um ator que é capaz de desafiar as construções discursivas pelas quais é entendido. Merchant (1989) coloca tanto os humanos quanto os não humanos no cenário histórico:

A relação entre o mundo humano e não humano é, pois, recíproca. Os humanos se adaptam às condições ambientais da natureza; mas quando os humanos alteram seu ambiente, a natureza responde por meio de mudanças ecológicas" (p. 8).

Uma compreensão clara da agência da natureza não humana não só enriquece o entendimento histórico, mas também catalisa uma ética ambientalista de parceria. Em Earthcare: Women and the Environment, Merchant (1996) relaciona a teoria do caos, que vê a natureza como uma "ordem desordenada", com a "ciência pós-clássica, pósmoderna", que é "uma ciência de conhecimento limitado, ou o primado do processo sobre as partes, e de contextos integrados dentro de sistemas ecológicos complexos e abertos" (p. 221). Ela nos instiga a ver a natureza como um "ator autônomo livre" que devemos respeitar como um parceiro igualitário merecedor de representação política. Merchant apresenta uma ética ambiental convincente e compreensível - se apenas nações, comunidades e indivíduos abraçassem uma ética de parceria!

Merchant (1996) apresenta um argumento indiscutível em favor da agência da natureza - citando enchentes, furacões e outros acontecimentos. Ela também coloca humanos e natureza em pé de igualdade, descrevendo a natureza como um "ator autônomo livre", "da mesma forma que os humanos são agentes livres e autônomos" (p. 221). Mesmo que esse modelo encoraje relações igualitárias entre humanos e natureza, a ideia de um "ator autônomo livre" talvez não se sustente. $O$ ator autônomo sugere um sujeito distinto, humanista, que não está envolvido com ou constituído por discursos, criaturas, sistemas ecológicos ou bioquímica. Embora o modelo de Merchant promova o ideal ético de considerar a natureza como uma entidade soberana em vez de um recurso para consumo desenfreado, é difícil imaginar a natureza-ou, até mesmo, humanos - como, em última análise, livres ou autônomos. Dessa forma, a ética de 
${ }^{5} \mathrm{~N}$. da T.: A palavra "dirt", em inglês, pode significar, entre outras coisas, lodo, lama, poeira solo. Optei pela palavra "terra", que me parece mais adequada ao contexto. parceria poderia isolar a natureza dos humanos ao propor uma noção de autonomia que não pode se desenvolver dentro de modelos de interdependência, sistemas ecológicos, ou saúde ambiental.

Concepções de agência não humana não precisam ser predicadas sobre um modelo humanista do indivíduo livre. De fato, alguns modelos pós-estruturalistas de subjetividade podem oferecer modos mais produtivos para conceituar a agência da natureza. O sujeito, em "Contingent Foundations", de Judith BUTLER (1992), por exemplo, se assemelha a vários dos atores que habitam o mundo-maisque-humano. Na formulação de Butler, o sujeito não é absolutamente "seu próprio ponto de partida". Na verdade, a agência resulta exatamente do modo como o sujeito é produzido por "matrizes de poder e de discurso" ( p. 9). Esse modelo discursivo de subjetividade é semelhante a um modelo ecológico no qual várias criaturas não humanas agem dentro de sistemas complexos e estão entrelaçadas com seu "ambiente", que nunca é apenas um pano de fundo, e, sim, a base de seu ser que eles, por sua vez, afetam e transformam. Apesar desses intrigantes paralelos, a concepção de agência de Butler (1992) precisaria ser substancialmente reformulada para fazer sentido para criaturas não humanas, já que ela descreve o exercício da agência como uma "reconfiguração intencional e significativa de relações culturais e políticas" (p. 12). O trabalho de Ladelle McWhorter e Karen Barad, no entanto, nos permite repensar completamente a agência material de forma que ela faça sentido para o que não é humano.

Em seu livro Bodies and Pleasures: Foucault and the Politics of Sexual Normalization, Ladelle McWHORTER (1999) faz uma ousada genealogia de seu próprio corpo, incluindo narrativas sobre "tornar-se branca" bem como de "tornar-se terra". ${ }^{5}$ McWhorter passou a ver a terra de forma diferente ao tentar cultivar seus próprios tomates. Ela observa que essa nova perspectiva foi uma "mudança surpreendente", já que a maioria das pessoas "tratam a terra como o lugar onde estão as plantas, como uma espécie de plataforma onde ficam as plantas... A terra é inativa. Inerte. Ninguém presta muita atenção a terra" (McWHORTER, 1999, 165). McWhorter (1999), no entanto, atribui a terra uma atenção bastante filosófica. Sua narrativa, na verdade, apresenta um surpreendente modelo de agência sem sujeitos. Depois de observar que a terra "não tem integridade", ela explica como, mesmo assim, ela age:

A terra não é algo particular ou identificável. Mesmo assim, ela age. Ela agrega e, dependendo da forma como agrega em um lugar específico, como se acomoda nos vários tamanhos de espaços vazios, 
cria um complexo sistema de filtragem de água e ar cujos ritmos ajudam a produzir mais terra das rochas expostas e a sustentar a vida microscópica necessária para transformar matéria orgânica morta novamente em terra. A terra se perpetua (p. 166).

A terra demonstra uma agência sem agentes, um tornar-se fundamental e perpétuo que acontece sem vontade, intenção ou esboço. Com efeito, a terra, uma substância bastante indistinta, é necessária para o surgimento de formas de vida menos difusas: "Toda distinção, integridade e identidade que possam ter as formas vivas, tudo provém da atividade daquela coisa indiferenciada e tão injuriada que chamamos terra" (McWHORTER, 1999, p. 167).

Pensar a agência da terra por meio da narrativa poética de McWhorter requer uma reconceituação da própria agência. Nem os modelos humanistas do sujeito racional, nem os modelos psicanalíticos do sujeito irracional são suficientes. Em vez disso, precisamos repensar completamente a própria natureza da agência, seguindo a linha do coiote trapaceiro de Donna Haraway (1991), que reconhece "o mundo como um agente espirituoso", com "um senso de humor independente" (p. 199). Enquanto que o trabalho de Haraway está repleto de figuras inspiradoras como o ciborgue, o primata, o coiote trapaceiro, o OncoMouse e o canino, todos reconceituando a agência em termos mais-que-humanos, o trabalho de Barad apresenta uma reconceituação mais abstrata da agência material advinda da física. A teoria de Barad (2003), na qual "a agência não é um atributo", mas "um 'fazer/ser' em sua intra-atividade" (p. 826), ajuda a fazer sentido da terra de McWhorter-ou, de uma outra perspectiva, é a terra que torna a teoria de Barad um pouco mais clara. Em "Posthumanist Performativity: Toward an Understanding of How Matter Comes to Matter", Barad (2003) oferece uma "elaboração da Performatividade - uma elaboração materialista, naturalista e pós-humanista - que dá à matéria o seu devido lugar como participante ativo no tornar-se do mundo, na sua constante 'intra-atividade'". Transportando as ideias de Niels Bohn para a teoria feminista, ela constrói a noção de "realismo agencial", no qual a agência "é liberada de sua órbita humanista tradicional":

\begin{abstract}
A agência não está alinhada com a intencionalidade ou a subjetividade humana. Nem apenas acarreta uma ressignificação ou outros tipos específicos de movimentos no âmbito de uma geometria social de anti-humanismo. A agência é uma questão de intra-ação; é uma representação, não algo que alguém ou alguma coisa tem... A agência não é absolutamente um atributo - é um "fazer"/"ser" em sua intra-atividade (p. 826).
\end{abstract}


${ }^{6} \mathrm{~N}$. da T.: Conforme o atomismo metafísico, relata são componentes anteriores a relações. Para Barad, no entanto, elas só podem existir no interior de fenômenos e não anteriormente a eles, daí o termo "relata-within-phenomena", aqui traduzido como relata-em fenômenos.
O fato de Barad considerar o conceito de "intraatividade" de Bohr em oposição à interatividade rejeita uma ontologia pela qual "coisas" precedem suas relações. Em vez disso, "relata" (em oposição a "coisas" individuais) "não são pré-existentes às relações; mas relata-em-fenômenos emergem por meio de intra-ações específicas" (2003, p. 815). ${ }^{6}$ O realismo agencial de Barad (1998), que rejeita o representacionismo em favor de um modo material-discursivo de performatividade, "contorna o problema de diferentes materialidades". Assim, "não há mistério algum sobre como a materialidade da linguagem poderia possivelmente afetar (por meio de qualquer mecanismo e em qualquer grau) a materialidade do corpo" (p. 108). Barad formula um modelo de materialidade, especificamente de agência material, que é absolutamente compreensível e absolutamente atraente.

Para nossos propósitos, é importante ressaltar que uma das razões que faz da teoria de Barad uma reconceituação tão potente e de tão longo alcance da materialidade é que ela não separa a natureza da cultura, o humano do não humano. De fato, Barad (1998) critica a teoria da materialidade de Butler por estar restrita a corpos humanos, e, em particular, a suas superfícies (p. 107). Afirma, ainda, que a materialidade "não é explicitamente natureza-fora-da-cultura" ( $p$. 109). A ontologia de Barad, que torna sem sentido as distinções entre "natureza" e "cultura", é uma importante intervenção na teoria feminista e cultural. Mesmo consideran-do que sua onto-epistemologia é extremamente valiosa para a filosofia feminista e ambientalista, penso que tais reconcei-tuações radicais não se firmarão tão rapidamente, sendo, portanto, ainda útil considerar as diferentes implicações de dotar corpos humanos e naturezas não humanas com agên-cia. Reconhecer a agência do mundo mais-que-humano é crucial para a ética ambiental por questionar a prática prevalente de "coisificação" (nos termos de Barad), o que, nesse caso, significa reduzir fenômenos animados, emergentes e intra-ativos a recursos passivos e isolados para uso e controle humano. Além disso, o reconhecimento de agência em tudo o que não é humano afirma a necessidade de lugares - urbanos, suburbanos, e, especialmente, "áreas selvagens" - em que o "fazer/ser" de criaturas, sistemas ecológicos e outras formas indistintas de vida possa florescer. Com efeito, um dos valores mais fundamentais da ética ambiental - o valor do "território selvagem" - pode ser entendido como uma espécie de agência material. Esse território pode muito bem ser definido como as contínuas intra-ações material-semióticas da natureza - ações que podem surpreender, incomodar, aterrorizar ou desconcertar os humanos, mas que, mesmo assim, são reconhecidas pelos ambientalistas como a própria matéria da vida. 
Porém, uma ética ambiental do espaço selvagem, não importa quão ampla, talvez não possa proporcionar um local adequado para a agência material do corpo humano. Mesmo que o desejo, especialmente o desejo sexual, possa ser celebrado como uma forma de agência material, quando nosso próprio corpo nos desconcerta, incomoda decepciona, ou adoece, essas ações são raramente valorizadas. Como argumenta Susan WENDELL (1996), o tom celebrativo da maioria dos trabalhos feministas sobre o corpo indica o fracasso em confrontar totalmente "a experiência do corpo negativo" (p. 167). Os estudos de deficiência buscam considerar outro tipo de agência corporal - corpos que resistem aos processos de normalização, ou se recusam a agir, ou agem de maneiras indesejáveis para aqueles que os habitam ou para outros. Mas, mesmo argumentando que pessoas que habitam corpos deficientes, corpos cronicamente doentes, ou corpos em sofrimento têm um bom motivo para desejar a transcendência do corpóreo e praticar "estratégias de desligamento", a própria exigência do corpo deficiente insiste que se reconheça uma agência corporal. Nas palavras de Wendell (1996), "o corpo pode ter uma vida própria complexa, grande parte da qual não podemos interpretar" (p. 175). Resumindo, a agência do corpo exige uma aceitação de imprevisibilidade e de desconhecimento.

Doenças crônicas, como lúpus ou artrite reumatóide, oferecem um exemplo tangível da agência "negativa" da corporalidade, já que os sintomas reais e sua gravidade podem variar de um dia para o outro e, mesmo, durante um mesmo dia. A dor se move. De repente, um joelho não funciona. O sol provoca uma dor flamejante. Além disso, como as doenças autoimunes são afetadas por um grande número de fatores conhecidos, suspeitos ou desconhecidos - como estresse, dieta ou as condições do tempo-, elas exemplificam a concepção de Barad de agência material como "'fazer'/'ser' em sua intra-atividade", na qual inumeráveis forças agem constantemente. Embora não haja dúvida de que uma completa compreensão dessa condição médica seja desejável, nem mesmo o conjunto de informações de médicos, pesquisadores, grupos de apoio e os dados fornecidos pelo próprio corpo podem resultar num entendimento claro e preciso, já que há muitas (quantas?) forças continuamente intra-agindo.

Sem minimizar a especificidade de uma pessoa que vive com doença crônica, há, obviamente, a noção de que todos os seres corporificados experimentam agências corpóreas, sejam elas positivas, negativas ou neutras. O reconhecimento de que o corpo tem suas próprias forças, interligadas e continuamente intra-agindo com matérias mais amplas e com forças sociais, econômicas, psicológicas e culturais pode ser não apenas útil, mas também ético. Num sentido mais 
óbvio, se não se pode presumir o domínio do próprio corpo, que tem "suas" próprias forças, muitas das quais não podem ser totalmente compreendidas mesmo com a ajuda do conhecimento e da tecnologia médica, não se pode presumir o controle do resto do mundo, que está para sempre intraagindo de formas incompreensivelmente complexas.

\section{Um pouco fora de alcance: o espaço epistemológico como espaço ético}

A epistemologia feminista e a filosofia ambiental já há muito reconhecem o impacto ético dos paradigmas e práticas epistemológicas. Não temos espaço, aqui, para esboçar as intersecções entre esses dois campos, mas podemos salientar dois exemplos de teoria ambiental feminista que encorajam modos de conhecimento mais prudentes e amplos-modos de conhecimento que não excluem as ações, o significado e o valor do mundo mais-que-humano. Donna Haraway (1991), em "Situated Knowledges: The Science Question in Feminism and the Privilege of the Partial Perspective", oferece um atraente modelo epistemológico que requer que

o objeto de conhecimento seja visto como um ator ou agente, não como uma base ou recurso, e nunca finalmente como escravo de um mestre que bloqueie a dialética em sua específica agên-cia e autoria de 'conhecimento objetivo'” (p. 198).

Haraway (1991) utiliza uma metáfora espacial para descrever a situação: "A objetividade feminista deixa espaço para surpresas e ironias no cerne de toda produção de conhecimento; nós não temos controle do mundo" (p. 199 [grifo nosso]). Podemos imaginar, talvez, que o coiote trapaceiro precisa de um tipo de espaço, ou hábitat, para ter sucesso.

Da mesma forma, Catriona SANDILANDS (1999) utiliza algumas metáforas espaciais para descrever sua "visão democrática radical que inclui a natureza não como uma presença positiva de construção humana, mas como um Outro enigmático e ativo" (p. 181). Ela argumenta que "a melhor forma de linguagem humana a respeito do espaço irrepresentável da natureza é aquela que valida a parcialidade e a multiplicidade e que não pode nunca achar que "está certa". O "espaço" epistemológico se torna ético na filosofia ambiental e na teoria feminista porque repele presunções de domínio humano que reduziriam a matéria da vida a meros "recursos" para o consumo humano. O espaço epistemológico precisa ser um lugar contíguo - sempre tão próximo quanto a nossa própria pele-e, mesmo assim, proporcionar um amplo espaço para que o mundo mais-que-humano possa agir e, ainda mais especificamente, intra-agir de formas surpreendentes. 
Permitir um espaço-tempo para intra-ações materiais inesperadas, sejam elas as ações de falcões fazendo seus ninhos nas alturas ou os efeitos de plantas geneticamente modificadas sobre as abelhas, borboletas, ou populações humanas, é uma forma de entender uma ética que abraça o mundo selvagem, mesmo desconfiando de paradigmas do selvagem que dividem os humanos da natureza e apagam a presença de povos indígenas.

É interessante perceber que alguns dos caminhos para abordar "o" corpo, ou, mesmo, nosso próprio corpo, às vezes se assemelham ao fato de conceber a natureza selvagem como um espaço externo, estranho, desconhecido e, talvez, inimaginável. Como registra a poeta e romancista Linda HOGAN (2001) em suas memórias, The Woman Who Watches Over the World, "no mundo da matéria o que é valioso reside. assim como nos sonhos, no subterrâneo, fora da visão humana, às vezes um pouco fora de alcance" (p. 137). As reflexões de Hogan (2001) imaginam o interior de seu próprio corpo como um espaço não familiar, no qual ela gostaria de "viajar":

Às vezes eu observo a roupagem de músculo e de carne que reveste esses ossos e me pergunto por que não consigo me curar, por que não posso mudar essa vestimenta, como alguns acreditam, e deixar os ossos livres, por que não posso viajar através da matéria do meu próprio corpo e tocar os órgãos, afrouxar os ligamentos que unem as partes como no corpo encontrado por Vesalius, a rede, o emaranhado que não existe na base deste cérebro humano nos separa dos animais tão abençoados. Mas o interior, a força vital, escorre por todas as nossas mãos, mesmo com nossos próprios corpos (p. 191).

Essa passagem começa com a repetição de "por que não posso", que funciona como um complicador das noções convencionais de subjetividade - o "eu" separado do corpo é muito menos onisciente e onipotente do que gostaria de ser. A frase seguinte coloca uma alternativa, uma epistemologia mais reduzida, na qual a imagem "todas as nossas mãos" sugere modos de conhecimento mais corpóreos e comunais, que reconhecem a agência evasiva das forças naturais. Significativamente, o "eu", aqui, não é mais o sujeito da frase, e, sim, "o interior, a força vital" que age ao "escorrer por todas as nossas mãos".

O relato poético de Hogan delineia uma jornada interior que termina com uma comunidade de mãos que buscam alcançar algo. O espaço que a "força vital" atravessa é um espaço transcorpóreo, que une a interioridade corporal com os processos da vida mais-que-humana. Esse espaço transcorpóreo pode nos ajudar a imaginar um tempo-espaço epistemológico no qual, por estarem sempre agindo e sofrendo ações, corpos humanos e naturezas não humanas se 
transformam, desdobram e, assim, resistem à categorização, conhecimento absoluto e controle. Como explica Moira GATENS (1996), o

\begin{abstract}
relato spinozista do corpo apresenta um corpo produtivo e criativo que não pode ser "conhecido" definitivamente, pois não permanece idêntico a si mesmo através do tempo. O corpo não tem uma "verdade" ou uma natureza "verdadeira" já que é um processo e seus significados e capacidades irão variar de acordo com seu contexto [...]. Esses limites e capacidades só podem ser revelados pelas contínuas interações entre o corpo e seu ambiente (p. 57).
\end{abstract}

Essas "contínuas interações entre o corpo e seu ambiente" exigem práticas de conhecimento que emergem dos múltiplos emaranhados de seres/fazeres/conhecimentos inter e intraconectados. Uma ética material transcorpórea deveria mudar sua atenção dos valores e ideais de indivíduos delimitados para as práticas situadas e em processo, que têm consequências imprevisíveis e de longo alcance para múltiplos povos, espécies e ecologias. A ética material transcorpórea ocorre num espaço "pós-humano", conforme descrito por Andrew PICKERING (1995): "um espaço em que os atores humanos ainda estão lá, mas agora inextricavelmente ligados com o não-humano, não mais no centro da ação e dando as cartas. O mundo nos cria no mesmo e único processo pelo qual o criamos" (p. 26).

\title{
Mapas de trânsito
}

Uma forma de mapear esse espaço pós-humano é focalizar no tráfego entre corpos e naturezas. Quais são alguns dos caminhos de ida e vinda da corporalidade humana para a substância do que não é humano? Como ambos os termos são transformados pelo reconhecimento de sua interconexão? Que posições éticas ou políticas emergem do movimento entre as matérias humana e mais-que-humana?

Talvez o exemplo mais palpável da transcorporalidade seja a comida, pela qual plantas e animais se tornam substância do humano. Mesmo que comer possa parecer uma atividade descomplicada, agências materiais peculiares podem ser reveladas no trajeto da terra para a boca. Ladelle McWhorter (1999) relata como sua busca pelo cultivo de um tomate real e saboroso termina não só com uma "admiração pelo solo", como vimos, mas também com um sentimento de afinidade com essa substância degradada. Após saborear um saco de Doritos, ela se dirige à composteira para jogar os últimos farelos, mas se detém:

"Não", pensei, "não posso jogar essa porcaria no meu solo". Atirei os farelos no lixo e peguei um último chip 
que restava. Já ia colocá-lo na boca, quando, na metade do caminho, me dei conta do que recém havia dito. Pela janela da cozinha, vi minha horta, meus canteiros, minha terra, e então meu olhar se dirigiu para meus dedos manchados de Doritos. Terra e carne. De repente me ocorreu que, apesar das diferenças, essas duas coisas que eu contemplava eram primas - não de primeiro grau, mas primas distantes. Desde então, não comprei nenhum saco de Doritos (p. 167).

Enquanto o último Dorito fica suspenso - no ar -, a narrativa epifânica o envolve com um reconhecimento bemhumorado de que essa precária sensação de parentesco entre terra e corpo pode não só elevar a terra ao status de um membro da família, mas, nesse caso, promover a própria substância do ser a algo que mereça cuidado e alimentação adequadas. Realmente uma família estranha, verde e ética. Podemos traçar o caminho literal pelo qual a terra se torna carne, por meio do tomate, uma sinédoque para todos os alimentos vegetais e a maioria dos animais que, em última análise, provêm da terra, embora McWhorter não insista nessa ideia, talvez porque enfatizar a comida, e não a própria matriz vital, nos apresente a natureza como algo comestível. É bem verdade que somos transformados pela comida que consumimos (como visto no filme Supersize Me), ${ }^{7}$ mas, em sua maioria, esse modelo de incorporação enfatiza os contornos do humano-o alimento desaparece no interior do corpo humano, que permanece solidamente limitado.

Em seu esclarecedor artigo "Incorporating Nature", Margaret FITZ-SIMMONS e David GOODMAN (1998) propõem um modelo de "incorporação" "como metáfora e como processo - como uma maneira interessante de trazer a natureza para o corpo da teoria social e, mais literalmente, para os corpos dos organismos vivos, inclusive os nossos" (p. 194). 0 complexo modelo de Fitz-Simmons e Goodman (1998), que considera a agência da natureza junto com as forças sociais, econô-micas e políticas, promove a noção de incorporação "para capturar a materialidade relacional de ecologias e corpos que caracterizam as redes de alimento agrícola" ( $p$. 216). Mesmo que essa formulação lance uma luz sobre como considerar as produções da natureza-cultura, em última análise, a produção de alimentos é um caso unilateral, pois o modelo de incorporação fica a um passo do consumo capitalista. Embora McWhorter comece com um simples desejo por um tomate, seu contexto caminha na direção oposta, movendo sua própria carnalidade até a terra, em vez de apenas incorporar os frutos da terra em seu corpo. A análise foucaultiana da corporalidade de McWhorter, que na maior parte de seu livros se refere não a questões ecológicas, mas a regimes regulatórios da sexualidade, 
chega até o solo, tornando-se uma completa redefinição do que constitui a substância da matéria.

Baseando-se em Spinoza em vez de Foucault, Moira Gatens também descreve corpos humanos que se abrem para o mundo mais-que-humano. A identidade do corpo humano

nunca pode ser vista como um produto final ou acabado como no caso do autômato cartesiano, uma vez que é um corpo em constante troca com seu ambiente. O corpo humano está radicalmente aberto ao mundo ao seu redor e pode ser composto, recomposto e decomposto por outros corpos" (GATENS, 1996, p. 110).

Enquanto que, num modelo de incorporação, o self humano permanece o mesmo, na leitura que Gatens faz de Spinoza o corpo humano nunca é estático porque suas interações com outros corpos sempre o modificam. Gatens (1996) explica que esses "encontros" com outros corpos são bons ou ruins, dependendo de eles ajudarem ou prejudicarem nossa constituição característica" (p. 110). Curiosamente, a compreensão que Spinoza tem do corpo se assemelha particularmente a alguns dos modelos de corporalidade do século XXI - como o do movimento de saúde ambiental - que alertam que certas "trocas com o ambiente" podem resultar em doen-ças, enfermidades e morte. De fato, os muitos protestos contra alimentos geneticamente modificados (GM) demonstram que esses alimentos podem não ser incorporados no corpo humano de forma benigna. Alimentos GM podem até ter efeitos não pretendidos na saúde de humanos ou outras criaturas, efeitos que a ciência pode levar décadas para descobrir.

Ao passo que as relações gastronômicas entre terra e estômago oferecem um exemplo bastante digerível do trânsito transcorpóreo, Vicki KIRBY (1997) apresenta um relato contraintuitivo sobre como a corporalidade humana se abre para o mundo mais-que-humano. Em seu fascinante livro Telling Flesh: The Substance of the Corporeal, Kirby (1997) apresenta uma provo-cante leitura da famosa frase de Jacques Derrida, "Não há nada fora do texto". Ela argumenta: "É como se o próprio teci-do da substância, a base do Ser, fosse esse intertexto mutável - uma "escrita" que ao mesmo tempo circunscreve e excede as divisões convencionais de natureza e cultura" (p. 61). De fato, Kirby (1997) abre a possibilidade de "que a natureza escreva ou que o corpo leia": "Pois se a natureza sabe escrever, então a pergunta 'O que é a linguagem' - ou, mais escandalosa-mente, 'Quem lê?' - fratura o sujeito cartesiano em seu funda-mento" (p. 127). Kirby (1997) amplia o modelo pós-estruturalista de textualidade a tal ponto, que seus termos mais básicos são radicalmente re-escritos: 
O que estou querendo evocar aqui é um "entendimento" que palavra e corpo estão completamente implicados, não porque "corpo" seja uma palavra mediadora daquilo que está sendo referido, mas porque a entidade de uma palavra, a identidade de um signo, o sistema da linguagem, e o domínio da cultura - nenhum deles está autonomamente fechado em si mesmo. Eles são todos emergentes dentro de um campo de força de diferenciações que não tem exterioridade num sentido absoluto (p. 127).

O comentário crítico de Kirby transforma o pós-estruturalismo num horizonte verdadeiramente pós-humanista, já que se recusa a delinear o humano, o cultural, ou o linguístico contra um fundo de matéria muda. Natureza, cultura, corpos, textos - tudo se desdobra num "campo de força de diferenciação" sem limite. Para McWhorter, Gatens e Kirby, aquilo que tem sido exclusividade do Humano expande num campo em que a substância da corporalidade humana -e, no caso de Kirby, até de sistemas linguísticos humanos - não é, em última análise, separável daquilo que é difícil não chamar de "natureza". Essas teóricas podem ser lidas como uma espécie de pós-escrito às muitas invocações feministas à natureza como um espaço não domesticado - literalmente não doméstico. Pois as paredes do recinto doméstico, que separariam o humano da natureza e definiriam o humano como tal, não podem ser encontradas em lugar nenhum, já que a corporalidade e a textualidade humanas se ampliam sem esforço - para o mundo mais-que-humano. Palavra, corpo e terra não são mais distintos.

Do ponto de vista da ética ambiental, pode ser perigoso fazer comparações entre a corporalidade humana e a natureza não humana, pois, de certa forma, isso replica os próprios dualismos que estão na raiz do problema. A natureza, para ser franca, tem como população uma miríade de mentes não humanas assim como matéria; não faz sentido igualar os muitos seres "culturais" autodirecionados, vivazes, comunicativos com a supostamente inerte "substância" da matéria. Val PLUMWOOD (1993), por exemplo, apresenta o convincente argumento de que, para combater os persistentes dualismos natureza/cultura, corpo/mente da cultura ocidental, devemos "reconceber a nós mesmos como mais animais e corpóreos, mais "naturais", e repensar a natureza como mais mental do que nas concepções cartesianas" (p. 124). De forma semelhante, Carolyn Merchant (1996), embora observe que uma das razões pelas quais as mulheres se tornam ativistas é "porque seus corpos, ou os corpos das pessoas de quem cuidam, são ameaçados por substâncias tóxicas ou radioativas" (p. xviii), não enfatiza a corporalidade como uma conexão entre o humano e o não humano, preferindo, como 
${ }^{8}$ Ver 0 trabalho de Elizabeth $A$. Wilson. vimos, "elevar" a natureza para o status de um "sujeito" político.

Concordo com Plumwood que é essencial para a política que as práticas e a ética ambientais continuem a articular compreensões estimulantes dos aspectos "mentais" da natureza - como as linguagens dos golfinhos e das abelhas, ou as culturas dos elefantes e dos chimpanzés - coisas que as pessoas têm se esforçado para negar. Sugeriria, no entanto, que permanecer dentro do espaço transcorpóreo, onde "corpo" e "natureza" são incluídos no mesmo material, constituído simultaneamente pelas forças da evolução, da história natural e humana, das desigualdades políticas, das contestações culturais, dos processos químicos e biológicos, e outros fatores demasiado numerosos para incluir aqui, torna as rígidas distinções entre "mente" e "matéria" impossivelmente simplistas. Assim, ao reformular os termos do debate, algo tão longe de ser glorificado como o solo pode ser entendido como um agente, e não (apenas) como a base para a ação de alguma outra coisa. Embora isso possa parecer um mero exercício filosófico, e de certa forma o é, as realidades e práticas materiais contemporâneas podem incentivar esse repensar filosófico, já que se tornou cada vez mais difícil separar o "humano" da "natureza". Como Haraway de forma tão presciente previu em seu manifesto ciborgue, no início do século $\mathrm{XXI}$, as dicotomias entre mente e matéria, cultura e natureza, não são mais portos seguros. Os exemplos são muitos. Aqui está um deles: o recente turbilhão de psicofármacos, notavelmente a famosa e infame popularidade do Prozac, torna impossível considerar a mente, as emoções, a psique ou o "espírito" humanos como algo separado da bioquímica e das redes neurais. ${ }^{8}$

Porém, mesmo se tornando mais difícil para os humanos entregar-se a ilusões de grandeza que nos coloquem bem acima de uma natureza ordinária, isso não significa, de uma perspectiva ambientalista, que devemos promover noções de espaço transcorpóreo que sejam, por definição, antropocêntricas, pois esse espaço pode ser imaginado como aquilo que circunda o humano. Mais especificamente, pode ser perigoso, de uma perspectiva ambientalista, permanecer na interface entre humano e natureza, uma vez que esse é o lugar, por excelência, da devastação ambiental causada pelo consumo (exagerado), pelos dejetos e pela devastação. Em resumo, talvez ainda seja melhor abraçar ideias ambientais de território selvagem, ou de respeito à "soberania" da natureza (como coloca Plumwood), ideias que ajudam a estabelecer limites para proteger a natureza da exploração e da degradação.

Mesmo que o ideal do território selvagem tenha ficado insustentável, tanto por causa de seu legado pernicioso de 
${ }^{9}$ Ver William Cronon (1996), "The Trouble with Wilderness; or, Getting Back to the Wrong Nature".
${ }^{10}$ Ver Alaimo (2001 e 1997). apagamento da presença de povos indígenas, quanto por promover uma desvalorização das várias "naturezas" que a maioria de nós na verdade habita, ${ }^{9}$ a sobrevivência de muitas espécies depende da criação de mais áreas onde criaturas selvagens e ecossistemas possam florescer. Alguns desses lugares podem incluir humanos envolvidos em práticas sustentáveis de sobrevivência. Penso, no entanto, que é possível defender o valor de lugares em que criaturas não humanas sejam soberanas ou selvagens e onde o impacto humano seja mínimo e, ao mesmo tempo, reconceituar várias rotas de conexão com aquele espaço aparentemente tão distante. Pois os corpos não humanos que habitam áreas selvagens são impregnados pelas mesmas toxinas que nossos corpos humanos, uma vez que essas toxinas se espalham por todo lugar, carregadas pela água, pelo ar e pelos tecidos de criaturas vivas que viajam. A transcorporalidade, nesse sentido, não precisa estar limitada a áreas contíguas ao humano, mas pode oferecer um caminho de conexão entre nossa existência corporificada e a sobrevivência de criaturas não humanas.

A necessidade de cultivar um sentido tangível de conexão com "a natureza" para encorajar o ethos ambientalista é ressaltada pelo difuso sentido de desconexão que representa "questões ambientais" como tópicos controláveis, distantes e dispensáveis. Veja-se, por exemplo, a negação do aquecimento global pela extrema direita, ou o uso despreocupado de pesticidas e herbicidas perigosos em casa (a atitude pode ser casual, mas o veneno não). Observe-se, também, a enxurrada de filmes de terror que começam com a ameaça de alguma criatura híbrida para terminar com uma triunfante transcendência humana sobre a natureza. ${ }^{10}$ Mas o sentido de parentesco, conexão e separação entre terra e corpo, palavra e mundo, precisa ser acompanhado por epistemologias amplas que permitam o desenrolar de inumeráveis intra-ações materiais. É interessante observar que a necessidade de áreas selvagens, que oferecem a várias criaturas o espaço para se desenvolverem, acompanha a necessidade de um espaço epistemológico que insiste que o mundo material intra-aja continuamente de maneiras demasiado complexas para serem previstas com antecedência. O "mundo material" inclui, aqui, ações humanas e intraações, bem como intra-ações de substâncias fabricadas pelo ser humano, todas as quais intra-agem com criaturas, forças e sistemas ecológicos naturais e com os corpos dos humanos. Os mapas de trânsito entre a corporalidade humana e a natureza não humana são infinitos. Mas, mesmo uns poucos esboços sugerem que interesses políticos e éticos, geralmente vistos como separados, estão inextricavelmente ligados pelo trânsito substancial entre corpos e naturezas.

Estudos Feministas, Florianópolis, 25(2): 909-934, maio-agosto/2017 929 


\section{O tempo-espaço transcorpóreo dos corpos tóxicos}

Pickering (1995), em The Mangle of Practice: Time, Agency, and Science, descreve cientistas como "agentes humanos num campo de agência material que eles se esforçam para capturar em máquinas" (p. 21). Ele argumenta que "as agências humana e material se encontram recíproca e emergentemente entrelaçadas nessa luta. Seus contornos emergem na temporalidade da prática" (PICKERING, 1995, p. 21). O tempo, portanto, fomenta uma espécie de "espaço" para as ações, ou agência, do mundo material para se revelar. Assim como a calandra da prática (científica) de Pickering capta a agência da natureza pela observação de como ela se desenvolve no tempo, a ética transcorpórea reconhece um tempo-espaço para o funcionamento de corpos humanos e não humanos. O espaço-tempo da transcorporalidade é um lugar tanto de prazer quanto de perigo - o prazer do desejo, da surpresa, da interconexão e da emergência viva, bem como os perigos da dor, da toxicidade, da incapacidade e da morte.

Infelizmente, não temos aqui nem espaço nem tempo para examinar o prazer. Então abordaremos um lugar com grande potencial para examinar o espaço ético da transcorporalidade: os corpos tóxicos. Sem dúvida, todos os corpos, humanos ou não, são, em menor ou maior grau, tóxicos no atual período histórico. Mesmo os humanos e os animais que estão distantes das zonas mais poluídas guardam um caldo químico em seu sangue e tecidos, como comprova o tão citado exemplo do leite materno contaminado dos Inuit. Como as substâncias químicas podem envenenar as pessoas que as produzem, o ambiente em que são produzidas, e as plantas e animais que acabam por consumi-las, o trânsito das toxinas revela a interconexão entre vários movimentos, como saúde ambiental, saúde ocupacional, movimentos trabalhistas, medicina ecológica, direitos da deficiência, vida verde, antiglobalização, direitos do consumidor e bem-estar infantil. O trânsito das toxinas pode, na verdade, praticamente impossibilitar os humanos de imaginarem que sua própria saúde e bem-estar estão desconectados da situação do resto do planeta, ou imaginarem que é possível proteger "a natureza" apenas por meio da criação de áreas distintas ou separadas em que "ela" seja "preservada". Em outras palavras, o espaço ético da transcorporalidade nunca está em outro lugar, mas sempre já aqui, mesmo que seja de forma mitigada ou catalisadora. O Greenpeace, uma organização ambientalista conhecida por suas táticas inovadoras, lançou recentemente uma campanha contra o mercúrio, encorajando as pessoas a enviarem uma amostra de seu cabelo para teste 
de contaminação por mercúrio. Uma ação como essa torna bastante palpáveis as campanhas pela conexão corporal entre indivíduos e o ambiente global, especialmente porque o Greenpeace, em retorno, informava cada participante sobre o nível de mercúrio em seu corpo, explicava o significado dessa quantidade em termos de possíveis efeitos para a saúde, e apresentava formas de minimizar a exposição ao mercúrio por meio de dietas e de atos políticos. Tomando outro exemplo, identificar o trânsito das toxinas pode nos permitir verificar que produtos químicos carcinogênicos são produzidos por algumas das mesmas companhias que vendem drogas para quimioterapia. Pode ser muito útil saber disso.

Em uma escala maior, é útil considerar que não é provavelmente possível, mesmo num "futuro previsível", estimar o número surpreendentemente crescente de interações químicas que podem ocorrer como resultado de "bilhões de quilos de produtos tóxicos rotineiramente emitidos" apenas nos Estados Unidos (Sandra STEINGRABER, 1997). O problema não é só, como Sandra Steingraber nos informa, que "dois terços dos produtos químicos mais utilizados ainda não passaram pelos testes mais básicos de potencial carcinógeno" ( $p$. 102), mas que muito pouco se conhece sobre como as várias combinações químicas inter- e intra-agem nos corpos e "ambientes" (1997, p. 281, 258). Steingraber (1997) defende o "princípio da precaução" que afirma, em parte, que

quando uma atividade levanta ameaças de dano à saúde humana ou ao ambiente, medidas de precaução devem ser tomadas mesmo que algumas relações de causa e efeito não estejam completamente estabelecidas pela ciência. Nesse contexto, o proponente de uma atividade, e não o público, deve arcar com o ônus da prova (p. 284).

Da perspectiva de todos nós, habitantes de lugares materiais, transcorpóreos tóxicos, o "princípio da precaução" pode bem resumir a noção do espaço epistemológico como espaço ético, pois ele emerge de uma compreensão científica e política da enormidade dos efeitos de agências materiais que os humanos nunca poderão mapear e certamente nunca vão dominar. O princípio da precaução funciona como um mapa de procedimentos prático e de bom senso e como uma ética transcorpórea que emerge de epistemologias mais restritas e mais responsáveis.

Voltando à teoria feminista, pensar através dos corpos tóxicos nos permite re-imaginar a corporalidade humana, e a própria materialidade, não como uma substância utópica ou romântica, que existe antes da inscrição social, mas como algo que sempre carrega traços da história, da posição social, da região e da distribuição não igualitária de risco. Com 
efeito, conforme coloca Sandra Steingraber (1997), se compararmos a composição de nossos corpos com anéis de árvores, "nossos corpos são também um tipo de pergaminho. O que está escrito lá - dentro das fibras de nossas células e cromossomos - é um registro de nossa exposição à contaminação ambiental" (p. 236). Os corpos tóxicos são produzidos e reproduzidos, ao mesmo tempo, pela ciência, pela cultura industrializada, pelo agronegócio, pelo consumo capitalista e por outras forças. Os corpos tóxicos não são, com certeza, essencialistas, já que são voláteis, emergentes, e em constante evolução, neles e por eles mesmos, mas também por entrarem em contato com diferentes tipos de produtos químicos ao mudarem de casa ou de emprego, ou ao encontrarem vários produtos e poluentes. Esses corpos são, certamente, pósHumanistas não só porque seus limites são excessivamente porosos, mas porque mesmo as experiências supostamente "individuais" e a compreensão que temos de nosso corpo são mediadas pela ciência, pela medicina, pela epidemiologia, e pelo redemoinho de sub-culturas, organizações, páginas de Web e revistas dedicadas a expor os perigos e a cultivar práticas e prazeres alternativos e revolucionários.

Embora não sejam algo para celebrar, os corpos tóxicos podem ajudar a remover a teoria feminista do falso dilema de ter que optar entre uma valorização romântica dos corpos e da natureza ou um distanciamento antiessencialista das bases de nossa existência. Como um exemplo particularmente vívido de espaço transcorpóreo, os corpos tóxicos insistem que o ambientalismo, a saúde humana e a justiça social não podem ser separadas. Eles nos estimulam a nos imaginar em constante intercâmbio com o "ambiente" e, talvez paradoxicalmente, a imaginar um espaço epistemológico que permita tanto o imprevisível tornar-se de outras criaturas, quanto os limites do conhecimento humano.

\section{Referências}

ALAIMO, Stacy. "Endangered Humans? Wired Bodies and the Human Wilds". Camera Obscura, v.40/41, p. 227-244, 1997. . Undomesticated Ground: Recasting Nature as Feminist Space. Ithaca: Cornell University Press, 2000. . "Discomforting Creatures: Monstrous Natures in Recent Films". In: ARMBRUSTER, Karla; WALLACE, Kathleen (Eds.). Beyond Nature Writing. Charlottesville: University of Virginia Press, 2001. p. 279-296.

ALAIMO, Stacy; HEKMAN, Susan (Eds.). Material Feminisms. Bloomington: Indiana University Press, 2007. p. 237-264.

BARAD, Karen. "Getting Real: Technoscientific Practices and the Materialization of Reality". Differences, v. 10, n. 2, p. 87-128, 1998. 
"Posthumanist Performativity: Toward an Understanding of How Matter Comes to Matter". Signs, v. 28, n. 3, p. 80131, 2003.

BIRKE, Lynda. "Bodies and Biology". In: PRICE, Janet; SHILDRICK, Margrit (Eds.) Feminist Theory and the Body: Reader. New York: Routledge, 1999. p. 42-49.

BORDO, Susan. "Bringing Body to Theory". In: WELTON, Donna (Ed.). Body and Flesh: A Philosophical Reader. Malden: Blackwell, 1998. p. 84-97.

BROWN BLACKWELL, Antoinette. The Sexes Throughout Nature. New York: G. P. Putnam's Sons, 1875.

BUTLER, Judith. "Contingent Foundations: Feminism and the Question of 'Postmodernism'”. In: BUTLER, Judith; SCOT, Joan W. (Eds.). Feminists Theorize the Political. New York: Routledge, 1992. p. 1-21.

CRONON, William. "The Trouble with Wilderness; or, Getting Back to the Wrong Nature". In: CRONON, William (Ed.). Uncommon Ground: Rethinking the Human Place in Nature. New York: Norton, 1996.

DE LAURETIS, Teresa. "Statement Due". Critical Inquiry, v. 30, n. 2, p. 365-368, 2004.

FITZ-SIMMONS, Margaret; GOODMAN, David. "Incorporating Nature: Environmental Narratives and the Reproduction of Food". In: BRAUN, Bruce; CASTREE, Noel (Eds.). Remaking Reality: Nature at the Millennium. London: Routledge, 1998.

GATENS, Moira. Imaginary Bodies: Ethics, Power and Corporeality. New York: Routledge, 1996.

HARAWAY, Donna. Simians, Cyborgs, and Women: The Reinvention of Nature. New York: Routledge, 1991.

. Companion Species Manifesto: Dogs, People, and Significant Otherness. Chicago: Prickly Paradigm Press, 2003.

HIRD, Myra J. "Naturally Queer". Feminist Theory, v. 5, n. 1, p. 85-89, 2004.

HOGAN, Linda. The Woman Who Watches Over the World: A Native Memoir. New York: W. W. Norton, 2001.

KIRBY, Vicki. Telling Flesh: The Substance of the Corporeal. New York: Routledge, 1997.

KRISTEVA, Julia. Powers of Horror: An Essay on Abjection. Tradução de Leon S. Roudiez. New York: Columbia University Press, 1982.

McWHORTER, Ladelle. Bodies and Pleasures: Foucault and the Politics of Sexual Normalization. Bloomington: Indiana University Press, 1999.

MERCHANT, Carolyn. Ecological Revolutions: Nature, Gender, and Science in New England. Chapel Hill: University of North Carolina Press, 1989.

Earthcare: Women and the Environment. New York: Routledge, 1996. 
PICKERING, Andrew. The Mangle of Practice: Time, Agency, and Science. Chicago: University of Chicago Press, 1995.

PLUMWOOD, Val. Feminism and the Mastery of Nature. New York: Routledge, 1993.

SANDILANDS, Catriona. The Good-Natured Feminist: Ecofeminism and the Quest for Democracy. Minneapolis: University of Minnesota Press, 1999.

STEINGRABER, Sandra. Living Downstream: A Scientist's Personal Investigation of Cancer and the Environment. New York: Vintage, 1997.

TUANA, Nancy. "Fleshing Gender, Sexing the Body: Refiguring the Sex/Gender Distinction". Southern Journal of Philosophy, v. 35 (Supplement), p. 53-71, 1996.

WENDELL, Susan. The Rejected Body: Feminist Philosophical Reflections on Disability. New York: Routledge, 1996.

WILSON, Elizabeth. Neural Geographies: Feminism and the Microstructure of Cognition. New York: Routledge, 1998.

[Recebido em 01/08/2016, e aprovado em 12/01/2017]

\section{Trans-Corporeal Feminisms and the Ethical Space of Nature}

Abstract: The article argues for a closer relationship between studies about the body, more specifically corporeal feminism, and environmental scholarship in philosophical and cultural studies. Because of the traditional association of nature with essentialism, the significance of materiality has tended to be overlooked in feminist theory. Through the use of the concept of "trans-corporeality" - the time-space where human corporeality is inseparable from "nature" or "environment" - as a theoretical site or epistemological space, richer and more complex modes of analysis may bring together "the entangled territories of material and discursive, natural and cultural, biological and textual".

Key words: Trans-corporeal feminism; More-than-human nature; Environmental feminist theory

Stacy Alaimo (alaimo@uta.edu) é distinguished teaching professor no Departamento de Inglês da Universidade do Texas, em Arlington, Estados Unidos, atuando nas áreas de estudos culturais, teoria ecocultural, humanidades ambientais, estudos animais, pós-humanismo, novo materialismo e literaturas americanas multiculturais. Seu trabalho se concentra nas interseções entre indagações teóricas e preocupações éticas e políticas, onde as questões acadêmicas colidem com a vida cotidiana, abrindo espaço para formas de pesquisa interdisciplinar que permitam o surgimento do inesperado. É autora da antologia Material Feminisms, com Susan J. Hekman (Bloomington: Indiana University Press, 2008); dos livros Undomesticated Ground: Recasting Nature as Feminist Space (Ithaca: Cornell University, 2000); Bodily Natures: Science, Environment, and the Material Self (Bloomington: Indiana University Press, 2010); Exposed: Environmental Politics and Pleasures in Posthuman Times (Minneapolis: University of Minnesota Press, 2016); Blue Ecologies: Science, Aesthetics, and the Creatures of the Abyss (em preparação). 